\title{
Active Ageing Roadmap - A Collaborative Networks Contribution to Demographic Sustainability
}

\author{
Luis M. Camarinha-Matos ${ }^{1}$ and Hamideh Afsarmanesh ${ }^{2}$ \\ ${ }^{1}$ Universidade Nova de Lisboa, Faculty of Sciences and Technology, Portugal \\ cam@uninova.pt \\ ${ }^{2}$ University of Amsterdam, Netherlands \\ h.afsarmanesh@uva.nl
}

\begin{abstract}
The application of the collaborative networks paradigm, and a new generation of collaboration-support platforms and tools, is a promising approach to supporting active ageing, and facilitating better use of the talents and potential of retired or retiring senior professionals. As such, collaborative networks can contribute to demographic sustainability. This paper introduces the results of a roadmapping initiative addressing the implementation of a new vision for extending professional active life. To support this vision, a strategic research plan for the development of a new digital ecosystem, covering the social, organizational, and technological perspectives, is proposed. A large number of stakeholders coming from different backgrounds contributed to the design and validation of this roadmap.
\end{abstract}

Keywords: Collaborative networks, active ageing, roadmap.

\section{Introduction}

Sustainability is currently a major challenge for the society. The usual notion of sustainability focuses on keeping, in the long run, a balanced system of environmental, economic, and social interacting dimensions or sub-systems. Achieving the optimal functioning of this system requires the contribution of many stakeholders which can be facilitated by a collaborative networks approach.

One important element of sustainability under the social sub-system is the demographic dimension, which leads to the term "demographic sustainability", usually understood as a constant population level related to an optimal growth rate of the population, corresponding to at least 2.1 fertility rate [1]. Another perspective of demographic sustainability is given by the relationship between working age and old population. Current demographic trends lead to a growing unbalance under this dimension, which has large impacts on the economic subsystem. In fact, as the proportion of older people in the population increases, it influences consumer patterns, business systems and capital markets, and put a considerable pressure on the social security systems. Particularly the ageing population increases the pressure on the state pension funds. Most pension schemas are designed so that pensioners' benefits are paid by those who are currently working. With relatively fewer people 
working and greater numbers claiming pensions, the long term sustainability of this "intergenerational contract" is in danger.

With the increase in both the percentage of senior citizens and expectation of life, it is timely to reassess the understanding of ageing and retirement, and questioning elderly's work, happiness, leisure, community involvement etc. and their interrelationships with respect to old age. Many elderly citizens, following retirement, quickly become marginalized and considered as a cost burden rather than a resource that is capable of "value creation" in the society $[2,3]$. This feeling of exclusion and isolation creates a vacuum in the life of the elderly citizens which in turn affects their health and well being.

More recently there is a growing recognition that the elderly population should not be considered a burden on the society but instead an asset that needs to be properly considered. A critical challenge for the society in respect to the "active ageing / ageing well" process [4] is to identify new organizational structures, approaches, and mechanisms so that elderly citizens do not feel excluded, and have the chance to use their knowledge and expertise in making valued contributions to the communities where they live. In particular the senior professionals / knowledge workers possess a number of skills and accumulated experience that need to be better used in value creation activities.

On the other hand, as the older population increases and the growth in the middleaged population slows down, older adults are becoming an increasingly important labour source. They typically bring maturity, dependability, and years of relevant experience to the workplace. Nowadays with more people remaining in good health at older ages and increasingly more jobs not involving physical strength, more old adults are able to continue working than ever before. Furthermore, active ageing, through a balanced combination of leisure, social interaction, and continued work involvement, is central to meeting citizen expectations and maintaining mental and physical health [5]. Retirement does not necessarily need to represent the end of the working period, but rather a career and lifestyle transition, where the retiree in principle has multiple options -- such as continuing to work (though perhaps at a different pace), returning to school for additional training or education, changing career, venturing into entrepreneurship, becoming more involved in volunteer work, or simply enjoying leisure and travel possibilities -- thus a mix of working, learning, relaxing, and trying new things can be foreseen as a desirable scenario.

ICT, and particularly high-speed pervasive broadband connectivity and web-based technologies, offer new opportunities to create new ways of working, facilitate social interaction, and reduce limitations imposed by location and time, thus increasing personal control. Nevertheless the sensitivity of the area, the dependency on the "parallel" introduction of new organizational models and creation of a new culture in society, the lessons learned with the limited success of existing associations of senior professionals, the risk of continuously developing technology that is not taken-up by target users, among others suggest the need for a careful analysis and a better planned approach towards what concerns new developments. In this context, roadmapping plays a fundamental role in the identification of a strategic research agenda and prioritization of needed actions.

In order to elaborate a strategic RTD plan in this direction a 27-month European initiative - ePAL (extending Professional Active Life) project - was launched in 2008 [6]. 
ePAL aimed to explore innovative ways to best facilitate and support active ageing and ensure a balanced and inclusive post-retirement lifestyle. A major hypothesis followed in ePAL is that ICT and particularly collaborative networks can provide an adequate framework for the implementation of effective support to active ageing [6].

\section{Organizational Forms}

In addition to the traditional initiatives focused only on socialization and entertainment activities for elderly, a number of other organizational forms and mechanisms, already existing or emerging, are focused on providing ways to help seniors remain professionally active after their retirement. In fact, as a response to the active ageing challenges, in recent years we can observe the emergence of a growing number of associations of senior professionals. Although bringing some benefits to their members, namely in the scope of socialization, the current model of these associations may lead to some form of "organized ghettos" for seniors with little inter-generational interaction. In order to guarantee a more holistic integration, the different socio-economic stakeholders must develop a whole series of business and behavioral models of varied structure, composition and characteristics to allow a variety of alternatives for the integration of senior professionals.

Nevertheless, associations of retired professionals represent an important organizational structure supporting active ageing. Therefore, ePAL conducted a survey on 29 of those associations in Europe and outside Europe in order to get a consolidated view of their practices. The main conclusion is that these organizational forms exist due to the fact that retired people refuse to accept the retirement as the end of a professional life, claiming instead for remaining professionally active. The aim of these associations is essentially to provide assistance to organizations and people that cannot afford market prices for such services, or assistance to organizations located in developing countries. Offered services are basically business consultancy and mentoring. The majority of them work

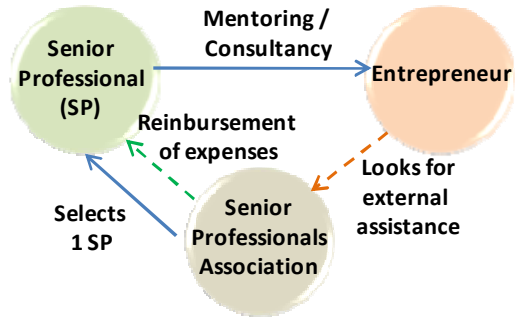

Fig. 1. Existing intermediation model on a voluntary basis sustaining themselves through membership fees and/or private or public funding and sponsorship. In terms of ICT, the majority of these organizations only use basic tools; nevertheless they are willing to use new and modern tools to help in their daily activities.

One example of operation is illustrated in Fig. 1. In this case an entrepreneur typically needs consultancy services in order to get a company project off the ground but cannot afford these services at market rates. The senior professionals association acts as an intermediary and selects the senior that best fits the needs of the entrepreneur from among its members. Typically, besides reimbursement of expenses, the senior professional does not receive remuneration from the entrepreneur although he/she might benefit from the association in other ways (e.g. prestige, experience with new methods, infrastructures, etc.). 
A more complex example is represented by Fig. 2. In this case it is assumed that a Governmental Institution has created a consultancy program for SMEs, with financial support from a Regional Government. However, different from the previous case, the consultancy services are delivered by a virtual team supported by an ICT platform, which is provided by some ICT company. The

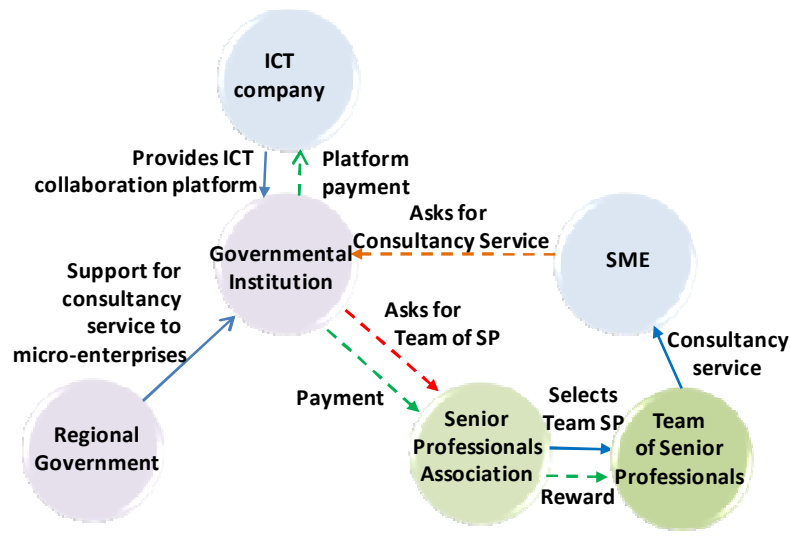

Fig. 2. Existing complex model association is in charge of assigning the work to a team of its members and putting them in contact with the recipient SME, in order to provide their consultancy services. For this collaboration the association receives some monetary remuneration. In order to offer the SME a high quality service, the Team of Senior Professionals includes experts in different areas (e.g. marketing, finance, management strategy, etc.) which jointly provide integrated mentoring and consultancy services. Senior professionals receive some reward (monetary or other).

Currently this case in which tasks are carried out by teams of senior professionals is quite rare. In most cases only one senior is involved in each task.

The existing associations are mostly composed of a "professional elite" i.e. people with high education and who had high positions in the socio-economic system before retirement. In most cases, these people have reasonable pensions, although varying from region to region, and therefore can afford to do voluntary (unpaid) activities. However, the number of people involved in such networks is not very high and many contacted seniors claim that it would be reasonable to receive some compensation for their contribution to value creation.

As illustrated in the above example, the effective involvement of seniors in the socioeconomic system needs to consider other stakeholders, namely intermediary entities and
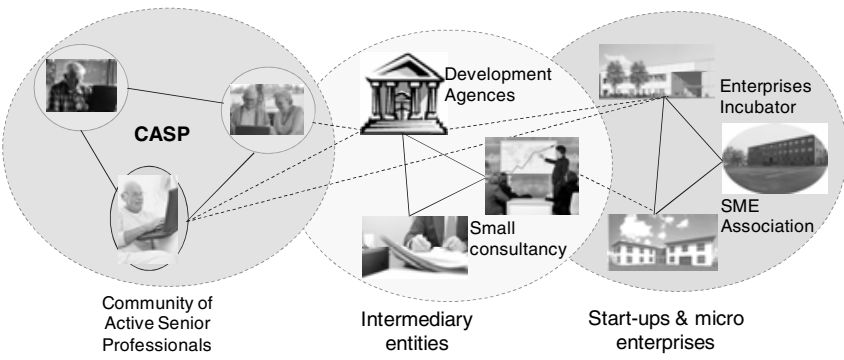

Fig. 3. Tri-partite networks the recipients of the services provided by seniors. Some of these entities are also organized in some form of association e.g. associations of SMEs, enterprise incubators or science parks, networks of regional 
development agencies and associated private (small) consultancy companies. Therefore ePAL proposes a tri-partite network model (Fig. 3) for these collaborative networks.

In recent years a considerable amount of tools have been developed in what concerns web-technologies, social networks and collaborative networks (see [7], for instance). Nevertheless new specialized platforms and support tools are needed specifically focused on the needs of seniors and considering the suggested tri-partite model.

\section{A Vision for a Desirable Future}

The application of visioning in defining and shaping the future direction of an organization or a society is increasingly becoming popular in today's world. A vision defines a desired future, while strongly interconnected with the framework that underlies the organizations or societies [8]. It is a deeply held picture of where a person, a group of people, an organization, or a society, wants to reach in the future. We create meaning in our lives by pursuing our future visions, and we refine our visions based on the meaning and trends we are discovering through our experience. A vision is the most inspiring future the society can imagine. Because of this ambitious prospect, the society can never truly achieve its vision. It rather works toward that vision.

Table 1. General vision statement of ePAL

\section{Core ideology:}

Building strong and cohesive societies across Europe that embrace active senior professionals to create value for individuals, communities and the economy

\section{Envisioned future:}

In the coming decade, a comprehensive paradigm will emerge in response to the challenges of demographic shift in Europe that enables a balanced active life for senior professionals, regardless of gender, capitalising on their talents and expertise, and facilitating value creation for the benefit of the individual, the economy and European society as a whole.

\section{Main desired facets:}

V1. Well founded reference model of the environment, specifying its: endogenous (structural, componential, functional, and behavioural) and exogenous (market, support, societal, constituency) elements, and their interlinks

V2. Well established technological infrastructure, support tools/services

V3. Policies promoting changes in societal perceptions of age and support mechanisms to motivate and empower seniors, taking account of cultural differences, giving them the choice to continue their professional active life

V4. Established organizational infrastructures that support the interaction between senior professionals and other actors in the socio-economic system, facilitating value creation

V5. Established policies, legal frameworks and ethical principles - regionally, nationally and across Europe - that motivate and support senior professionals and other socio-economic actors and regulate their interactions

A fundamental prerequisite for developing a vision for the desired future for active ageing is to identify both: the key drivers (i.e. the main driving forces in the market and society) and their related trends regarding the ePAL environment. A wellconceived vision consists of two major components, namely, the core ideology and the envisioned future [9]. Core ideology is the first primary component of the vision 
framework which consists of two parts: core values and core purpose. Core values are the essential and enduring tenets of an organization or society. Core values have intrinsic value and importance to those inside the organization or society. Core purpose however points to certain fundamental reason for society to exist. Envisioned future is the second primary component of the vision framework which consists of 2 parts: a long-term audacious goal and a vivid description or desired facets of what it will be like when goals are achieved.

In this research, to comprehensively cover the most important aspects related to a desired vision for ePAL, three main perspectives that are required to be addressed were identified. Namely, the vision of a desired future for active ageing shall cover its social perspective, its organizational perspective and its technological perspective. Tables 2, 3 and 4 show the instantiation of the vision according to these perspectives.

Table 2. Vision - social perspective

In the coming decade, extending active professional life will be a high priority strategy across Europe. European societies will mature to accommodate demographic shift through supporting and empowering senior professionals to fulfil their potential as active participants in the economy. Attitudes amongst individuals and organisations will evolve to embrace senior professionals as a value-creating pool of talent, thereby supporting and promoting equal opportunities in active aging. Both senior and young professionals will derive greater benefit from the exchange of knowledge and experience. As the social environment evolves, new support mechanisms will arise to sustain an aging but more active and inclusive population.

\section{Main desired facets:}

VS1. New mechanisms to enhance positive understanding and perception in society regarding the value of the abilities, skills and experience of individual senior professionals in the economy, taking account of gender

VS2. Mechanisms to build awareness, and to motivate senior professionals to join communities of active senior professionals

VS3. Mechanisms to support cross-cultural interactions among senior professionals as well as to the active labour force addressing barriers to communication

VS4. Mechanisms to support a balanced economic benefits sharing among the entire society including senior professionals

VS5. New mechanisms to help articulate the collective needs of seniors across national boundaries

VS6. Mechanisms to support cross generational interaction between seniors and younger citizens; fomenting inter-generational solidarity and understanding within the EU

VS7. Mechanisms to capitalize on the increased sense of trust and understanding which comes through leveraging seniors' social capital

Table 3. Vision - organizational perspective

In the coming decade, the primary organisational stakeholders - governments, intermediaries, businesses and unions - will adopt positive, proactive and coordinated policies and approaches that enable seniors to choose to continue their professional active life. As a consequence, senior professionals will enjoy new opportunities and a new market space of senior skills will be created, benefiting businesses and strengthening the wider European economy. 
Table 3. (continued)

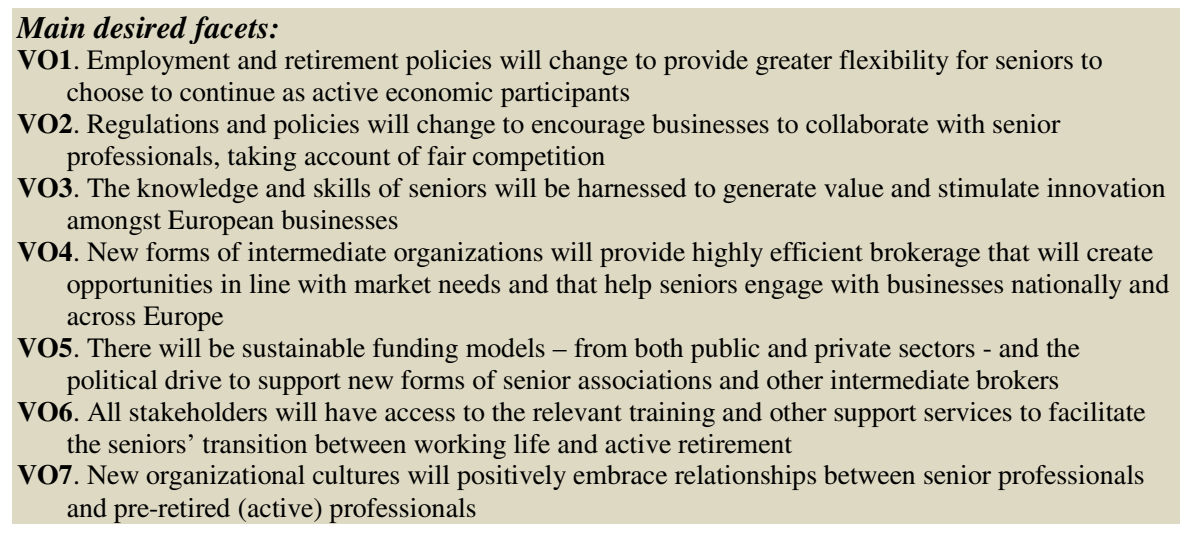

Table 4. Vision - technological perspective

In the coming decade, technology will facilitate and enable the continued active involvement of senior professionals in the socio-economic system. Through engagement with end-users, novel ICT collaboration platforms and tools will be developed that catalyse the creation of new organisational forms that connect and empower all stakeholders and facilitate the interaction between them. This technology will be accessible to all, 'senior friendly' and will enable seniors to expand their capabilities, leave a legacy and create value.

\section{Main desired facets:}

VT1. Advanced collaboration support services, including (virtual) teams' formation and management

VT2. Development of collaboration ontology supporting variety of stakeholders

VT3. Support for user-generated knowledge assets

VT4. "Configure yourself "based philosophy infrastructure

VT5. Easily adaptable and customizable user interfaces

VT6. Affective computing and context aware enriched environments

VT7. Support for establishment of trust among stakeholders

VT8. Tools supporting the process of value creation

VT9. Novel contractual and cooperation agreements, including negotiation support

VT10. Advanced marketing and brokerage services

VT11. New networking models for elderly communities' involvement with the socio-economic system

VT12. Security and ethical / privacy support.

\section{Strategic Actions Plan}

The elaboration of a plan of strategic actions is a fundamental step in roadmapping. Such actions, when successfully implemented, shall take the society from its current situation to a desirable future, as stated in the proposed vision [10]. The process of formulating such actions starts with an intense brainstorming activity within a small group of experts. The gap analysis, i.e. the identification of the "distance" between the current situation and the desired future, is an important element in this process [11]. In this formulation some base principles were followed: 
- Consider the needs according to the social, organizational, and technological perspectives of analysis and thus identify suitable actions for each of these areas.

- Keep the number of actions in each focus area relatively small (up to 6) in order to facilitate focused discussion.

- Ensure that the proposed actions cover all stated facets of the vision.

- Propose actions that although ambitious, are feasible considering the current situation (baseline) and trends, and that take into account the results of the gap analysis.

The following tables introduce the proposed set of strategic R\&D actions [10] that resulted from the roadmapping process conducted within the ePAL consortium and the extensive discussions held with stakeholders during several regional Consensus Building Events. The actions shown below reflect already the extensive feedback received in those events.

Considering the need to address technological developments within a socioorganizational context, similarly to the vision statement, the proposed actions are grouped into three major areas: social perspective actions, organizational perspective actions, and finally technological perspective actions.

Table 5. Proposed actions under the social perspective

S1: Value identification and communication. Promote socio-economic studies that identify the unique value senior workers bring to the workplace (experience, compensation flexibility, etc.) as well as their motivation and value systems, investigate new ways of senior workers interacting with the socio-economic system and communicate findings to seniors, employers, unions and to the society as a whole.

S2: Leveraging skills and talents. Design/develop mechanisms for skills/talent identification, categorization and improvement that assess acquired experience, provide career transition advice and support skills-enhancement to maximize the potential of seniors.

S3: European Senior Space facilitation. Promote dialogue and consensus around issues of technology, culture and socio-economic participation, creating links between existing and emerging senior associations and groups to develop a single, powerful voice for senior professionals across Europe.

S4: Facilitating inter-generational interaction. Investigate the barriers and potentials for cross generational interaction and collaboration between senior professionals and younger people, and fund/promote programmes and technology development that support and facilitate this interaction/collaboration.

S5: Improving working practices. Investigate new models of working practices and related reward and taxation models for senior professionals, taking account of issues of work-life balance, aging well and gender, and promote the findings in order to positively influence societal perception of older workers.

S6: Developing training and awareness. Design / develop ICT and collaboration training programs for seniors, and promote awareness and usage of collaboration technologies. 
Table 6. Proposed actions under the organizational perspective

O1: Enhancing policy and legislation. Identify and assess current national and European policy, legislation and incentives relevant to active participation of seniors in the socioeconomic system and recommend new approaches that lower barriers and promote and support active aging.

O2: Keeping links. Investigate new mechanisms that forge mutually beneficial relationships between seniors and their former employers

O3: Creating organizational structures. Investigate and promote new roles, governance rules and organizational forms for communities of active senior professionals to enhance inter- and intra-community collaboration and to create new opportunities for member engagement.

O4: Improving mediation and brokerage. Characterize and design new roles and modes of operation for intermediate organizations, both public and private, that provide brokerage and assistance to better facilitate integration and collaboration between senior professionals and the socio-economic system.

O5: Guiding career transition. Define new programmes and realistic practices that prepare for and guide the successful transition of senior professionals from full employment to active retirement, taking account of issues of gender, profession and local context.

O6: Meeting and creating market demand. Explore the best fit between capabilities of senior professionals and market demand and identify new channels to harness these resources and potentials in order to generate value and stimulate innovation amongst European businesses, thus supporting the economy.

Table 7. Proposed actions under the technological perspective

T1: Developing conceptual models. Establish formal conceptual models for people's professional life cycle and the support environment for active ageing.

T1.1 - Establish a reference model for extension of professional active life and active ageing.

T1.2 - Elaborate common ontologies for communities of senior professionals.

T1.3 - Develop contractual and business models for communities of senior professionals.

T2: Generating adaptive solutions. Develop and integrate self-adaptive and configurable technology solutions in ICT collaboration environments facilitating technology acceptance and enabling customization for/by seniors.

T2.1 - Develop self-adaptive interface systems.

T2.2 - Develop self-customizable collaboration environments empowering seniors to better use ICT.

T2.3 - Develop technology assistance wizards.

T2.4 - Increase involvement of seniors in the design of new technologies for seniors.

T3: Building collaboration platforms. Develop open ICT collaboration platforms for communities of senior professionals that promote human interaction and socialization and are enhanced by affective computing, context awareness, and trust establishment.

T3.1 - Develop advanced functionalities and systems for management of communities of senior professionals.

T3.2 - Develop affections / emotions management systems for communities of senior professionals.

T3.3 - Design and support governance systems for communities of senior professionals.

T3.4 - Develop trust building management systems for communities of senior professionals.

T4: Building collaboration tools. Design and develop collaboration support tools and systems to facilitate value creation, considering the specific needs of senior professionals. 
Table 7. (continued)

T4.1 - Develop marketing and brokerage support tools for communities of senior professionals.

T4.2 - Develop tools for virtual team creation, negotiation and e-contracting.

T4.3 - Develop tools for virtual team management and collaborative problem solving support.

T4.4 - Develop models and tools for management of Intellectual Property and performance.

T5: Leveraging legacy. Develop environments that empower seniors to leave a legacy capitalizing on their valuable and transferable personal / professional experience.

T5.1 - Define conceptual models of talents and develop user-centred knowledge acquisition tools

T5.2 - Create reward mechanisms (system of incentives) to attract user-generated knowledge.

T5.3 - Develop knowledge assets assessment and intellectual property models.

T5.4 - Mechanisms to promote inter-generational inheritance.

T6: Elaborating behavioural models. Develop approaches that discover patterns and model "the evolution of senior professionals' interests and their involvement in the socio-economic system" and "the behaviour and emotional health of senior professional networks".

T6.1 - Develop a conceptual base for behavioural modelling.

T6.2 - Develop data-mining / machine learning approaches for behavioural patterns discovery.

T6.3 - Develop forecasts and simulation methods and tools for behavioural analysis.

T6.4 - Develop models and tools for emotional health management.

As previously mentioned, an important assumption in this roadmapping initiative is that the collaborative networks paradigm provides a useful context for more effective active ageing support and thus contributing to demographic sustainability. Therefore, the development of reference models, collaboration platforms, and collaboration support tools specifically oriented towards the facilitation of the continuation of the involvement of senior professionals in the socio-economic system is a major goal.

Certainly considerable progress has been made in recent years in the area of collaborative networks, accompanied by rapid developments in computer networks and web-based technologies. Thus the proposed actions for the technological perspective take account of these trends, and focus on the specificity of active ageing and particularly on support to the extension of active professional life.

As the main focus of ePAL is on a roadmap for ICT development, the actions under the technological perspective (Table 7) are more detailed than the actions under the other perspectives.

The following diagrams show the proposed time sequence for the implementation of the actions.

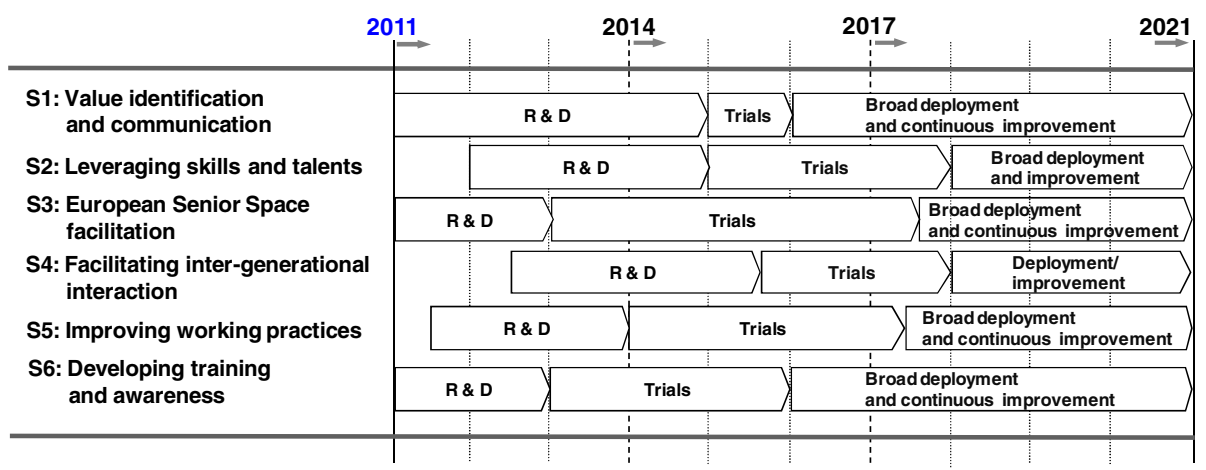

Fig. 4. Time sequence for actions under the social perspective 


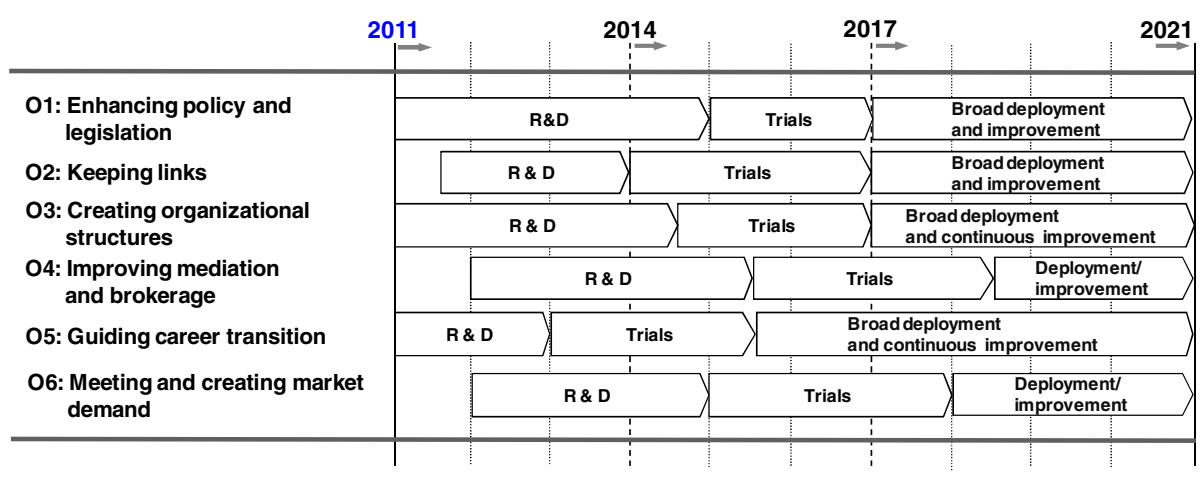

Fig. 5. Time sequence for actions under the organizational perspective

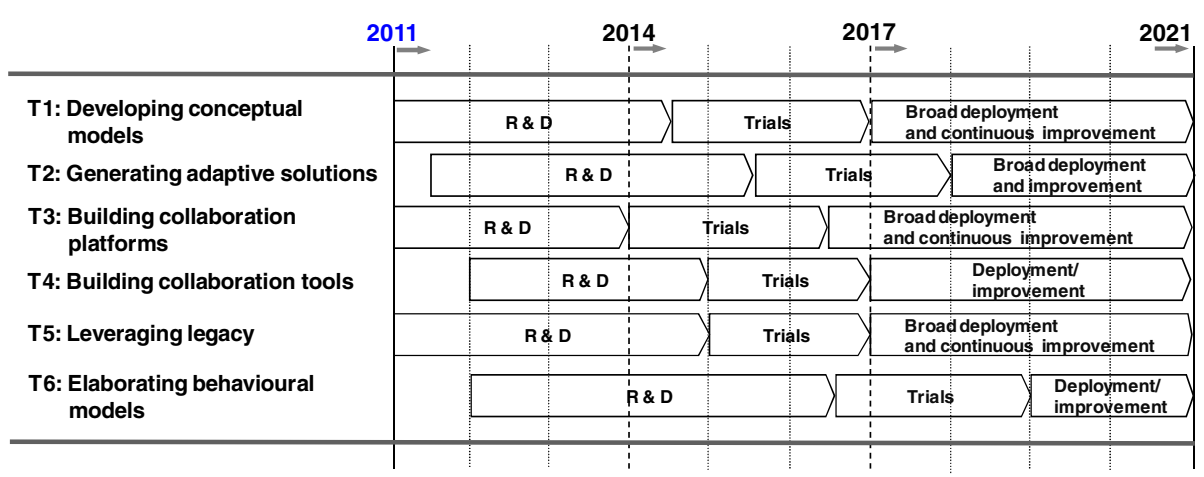

Fig. 6. Time sequence for actions under the technological perspective

In the above diagrams three modalities of implementation are considered:

- $\underline{R \& D}$ - focusing on fundamental research and prototype development / proof of concept, aimed at addressing longer term challenges.

- Trials - oriented towards the development of pilots and validation scenarios that allow verification and refinement of the results of previous phase with the objective of facilitating the development of innovative products and services.

- Broad deployment and continuous improvement - aiming at large scale validation - large pilots - of new technologies and services, as a mechanism to facilitate their take-up by society.

\section{Roadmap Validation}

The proposed vision statements and strategic actions plan resulted from a multi-stage construction and validation process. An initial formulation was prepared by the ePAL consortium following a series of consultation workshops and brainstorming sessions. Once a set of strategic actions emerged as a result of the brainstorming exercise, it was then necessary to proceed with a verification of those actions. The adopted 
verification process, at this stage of the roadmapping process, comprised two main activities: (i) Verify that the set of proposed actions adequately cover all stated facets of the vision. (ii) Assess the feasibility of each action considering the results of the gap analysis. Figure 7 illustrates the first step of validating the roadmap results for the action T5 under the technological perspective.

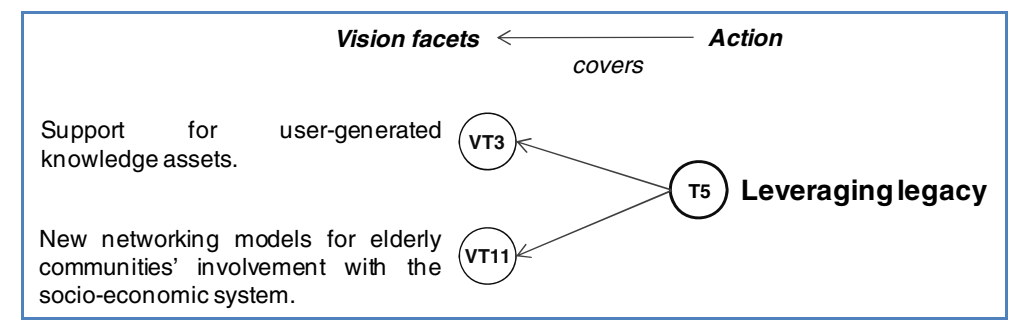

Fig. 7. Covering the vision facets - organizational perspective

Regarding the second step of validation, related to feasibility, the adopted approach was to consider how the strengths and limitations at European level identified in the gap analysis facilitate or make difficult the implementation of each action. Fig. 8 shows the result. This verification needed to be conducted by experts and depends on the perception of each individual according to his/her background knowledge. Therefore a qualitative scale (scale: Moderate, Hard, Very Hard) was adopted.

\begin{tabular}{|c|c|c|c|c|c|}
\hline \multicolumn{2}{|c|}{$\begin{array}{c}\text { Social } \\
\text { perspective }\end{array}$} & \multicolumn{2}{|c|}{$\begin{array}{l}\text { Organisational } \\
\text { perspective }\end{array}$} & \multicolumn{2}{|c|}{$\begin{array}{c}\text { Technological } \\
\text { perspective }\end{array}$} \\
\hline $\mathrm{S} 1$ & Moderate & $\mathrm{O} 1$ & Hard & $\mathrm{T} 1$ & Very hard \\
\hline $\mathrm{S} 2$ & Hard & $\mathrm{O} 2$ & Moderate & $\mathrm{T} 2$ & Very hard \\
\hline S3 & Hard & $\mathrm{O} 3$ & Moderate & T3 & Moderate \\
\hline S4 & Moderate & $\mathrm{O} 4$ & Very hard & $\mathrm{T} 4$ & Hard \\
\hline S5 & Very hard & $\mathrm{O} 5$ & Hard & T5 & Very hard \\
\hline S6 & Moderate & O6 & Very hard & T6 & Very hard \\
\hline
\end{tabular}

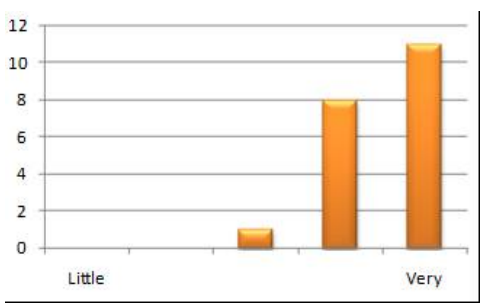

Fig. 8. Feasibility assessment

Fig. 9. Example of agreement with ePAL vision

The last phase of the project was focused on the refinement and consensus-building among relevant stakeholders. For this purpose, a number of Consensus Building Events were organized in different regions of Europe, namely Porto, Seville, London, Madrid, Maastricht, Lisbon, and Thessaloniki, involving more than 170 experts from different fields.

Fig. 9 illustrates the level of agreement with ePAL vision as voted by participants in one of these events. Fig. 10 shows the level of prioritization of actions as a result of voting by the consulted stakeholders. 

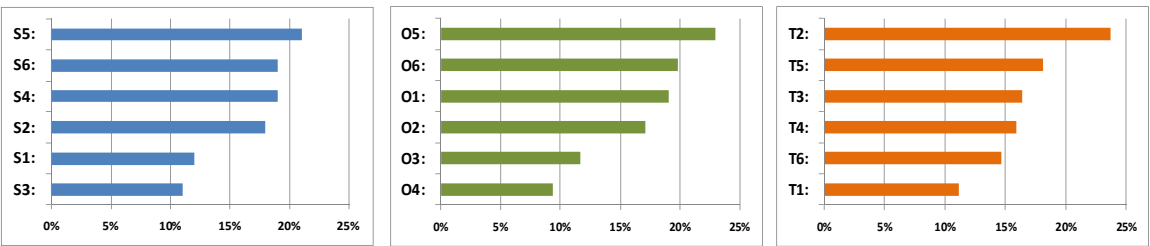

Fig. 10. Prioritization of actions

This prioritization, combined with the expected difficulty identified in the feasibility assessment, can give decision makers important elements when deciding on research resources allocation.

\section{Conclusion}

Increase in aged population is a critical issue in sustainability. As the expectancy of a longer and healthy life increases, the issue of extending the active professional life of senior people becomes an important topic. Such extension, if properly balanced with leisure and social activities, is likely to: (i) Facilitate active ageing, keeping seniors involved in, and contributing to, society; (ii) Generate additional income to help them maintain their standard of living and to support the wider economy, thus responding to the demographic sustainability challenges.

In this process, avoiding isolation and loneliness or even the creation of "elderly ghettos" is a major concern. ICT can be an important enabler in facilitating the creation of collaborative networks involving not only communities of seniors, but also potential recipients of their services and intermediary entities in a multi-level network. The collaborative networks paradigm supported by relevant technologies can also facilitate inter-generational interactions and thus contribute to the avoidance of ghettos.

The systematic roadmapping process behind the proposed research agenda as well as the extensive validation process involving a large community of stakeholders, are important factors for providing confidence in the adequacy of the proposed roadmap. Nevertheless, as normal in any "futures planning" initiative and taking into account the impossibility of adequately foreseeing the future, a roadmap is a dynamic construct that needs to be periodically revised alongside its implementation, taking into account new trends as they inevitably emerge.

\section{Acknowledgements}

This work was funded in part be the European Commission through the ePAL project. The authors also thank the contribution of their partners in the ePAL project as well as the multiple stakeholders involved in the consensus building workshops. This work is now being continued in the scope of the BRAID project, also funded by EC. 


\section{References}

1. Roca, M.N.O., Leitão, N.: Demographic Sustainability In Portugal: Towards a Typology. In: 14th European Colloquium on Theoretical and Quantitative Geography, Tomar, Portugal (2005)

2. HSBC Insurance: The future of retirement - The new old age (May 2007), http://www.hsbc.com/1/PA_1_1_S5/content/assets/retirement/ge nder_perspective_eurasia_africa_1.pdf

3. WHO: Active Aging: A Policy Framework, WHO/NMH/NPH/02.8, World Health Organisation report 2002 (2002)

4. Camarinha-Matos, L.M., Afsarmanesh, H.: Collaborative mechanisms for a new perspective on active ageing. In: Proceedings of DEST 2009 - 3rd IEEE Int. Conference on Digital Ecosystems and Technologies, Istanbul, Turkey, June 1-3 (2009)

5. Wilson, P., Johnson, K., Buller, W.: Ageing well in a connected world: Smarter care, smarter participation. CISCO Internet Business Solutions Group (December 2008)

6. Camarinha-Matos, L.M., Afsarmanesh, H.: The Need for a Strategic R\&D Roadmap for Active Ageing. In: Leveraging knowledge for innovation in Collaborative Networks, pp. 669-680. Springer, Heidelberg (2009)

7. Camarinha-Matos, L.M., Afsarmanesh, H., Ollus, M. (eds.): Methods and tools for Collaborative Networked Organizations. Springer, Heidelberg (2008)

8. Afsarmanesh, H., Camarinha-Matos, L.M., Msanjila, S.: A Well-conceived Vision for Extending Professional Life of Seniors. In: Camarinha-Matos, L.M., Paraskakis, I., Afsarmanesh, H. (eds.) Leveraging knowledge for innovation in Collaborative Networks, pp. 681-692. Springer, Heidelberg (2009)

9. Cummings, T.G.: Organization Development and Change. Thomson South-Western (2005)

10. Camarinha-Matos, L.M., Afsarmanesh, H., del Cura, A., Playfoot, J.: ePAL Roadmap for Active Ageing - A Collaborative Networks Approach to Extending Professional Life. In: Proceedings of AGEmap Workshop / Pervasive Health 2010 conference, Munich, Germany, March 22 (2010)

11. Leonard, W., Afsarmanesh, H., Msanjila, S., Playfoot, J.: Exploring the Gap for Effective Extension of Professional Active Life in Europe. In: Camarinha-Matos, L.M., Paraskakis, I., Afsarmanesh, H. (eds.) Leveraging knowledge for innovation in Collaborative Networks. Springer, Heidelberg (2009) 